\title{
Infections of Intestinal Helminth at Two Species of Field Mice, Apodemus agrarius and $A$. Peninsulae, in Gangwon- do and Chungcheongnam-do, Korea
}

\author{
Jae-Hyung Lee ${ }^{1,2, \uparrow}$, Shuang Gong ${ }^{1,2,}$, Yung Chul Park ${ }^{3, \dagger}$, Hyun-Ju Kim ${ }^{4}$, In-Wook Choi ${ }^{2}$, Young-Ha Lee ${ }^{1,2 *}$ \\ ${ }^{1}$ Department of Medical Science and ${ }^{2}$ Department of Infection Biology, Chungnam National University School of Medicine, Daejeon 35015, Korea; \\ ${ }^{3}$ Department of Forest Environment Protection, College of Forest and Environmental Sciences, Kangwon National University, Chuncheon 24341, \\ Korea; ' Microbial Safety Team, National Institute of Agriculture, Rural Development Administration, Wanju-gun, Jeollabuk-do 55365, Korea
}

\begin{abstract}
Rodents are important reservoirs of diseases affecting people and livestock, and are major sources of parasite contamination of agricultural products. We surveyed the infection status of intestinal helminths in 2 species of field mice, Apodemus agrarius and A. peninsulae, captured in the agricultural fields of Gangwon-do and Chungcheongnam-do, Korea. Total 83 mice (57 A. agrarius and 26 A. peninsulae) were collected in 2 surveyed areas, and the intestines of each mouse were opened with scissors, and then intestinal contents were examined with microscope. Total 6 species of intestinal helminth were detected in 61 (73.5\%) out of 83 mice examined. Four species of nematode, i.e., Nippostrongylus brasiliensis, Aspiculuris tetraptera, Heterakis spp. and ascarid, were found in 40 (48.2\%), 14 (16.9\%), $11(13.3 \%)$ and 13 (15.7\%) mice respectively. One species of cestode, Hymenolepis diminuta and 1 unidentified egg were also detected in the intestines of $14(16.9 \%)$ and $1(1.2 \%)$ mice, respectively. Conclusively, this study identified 5 helminth species in the gastrointestinal tracts of wild rodents captured in some areas in central and northern Korea, and $N$. brasiliensis was the most prevalent (dominant) species rather than zoonotic ones.
\end{abstract}

Key words: Intestinal helminth, wild rodent, Gangwon-do, Chungcheongnam-do

Rodents are vital components of various ecosystems, either as prey or as disease carriers and reservoirs. Parasite eggs disseminate via rodent droppings on agricultural fields, stored grains, and household foodstuff, and are responsible for the spread of various diseases $[1,2]$. There were some reports about rodent parasites in Korea [3-8]. Sohn et al. [3] identified more than 11 species of intestinal helminths (4 nematode spp., 5 trematode spp., 1 cestode spp. and unidentified egg) in Apodemus agrarius captured in Hapcheon-gun, Gyeongsangnam-do, Gurye-gun, and Jeollanam-do, Korea. Lee et al. [4] detected three nematode, 2 trematode, and 2 cestode species in the intestines of A. agrarius and A. peninsulae captured in northern Gangwon-do, Korea. Chai et al. [5,6] reported A. agrarius infection with Plagiorchis muris and echinostomes near the demilitarized zone (DMZ) in northern Gyeonggi Province. Recently,

\footnotetext{
- Received 1 September 2017, revised 9 May 2018, accepted 14 May 2018.

*Corresponding author (yhalee@cnu.ac.kr)

† Jae-Hyung Lee, Shuang Gong and Yung Chul Park contributed equally to this work.

(c) 2018, Korean Society for Parasitology and Tropical Medicine

This is an Open Access article distributed under the terms of the Creative Commons Attribution Non-Commercial License (http://creativecommons.org/licenses/by-nc/4.0) which permits unrestricted non-commercial use, distribution, and reproduction in any medium, provided the original work is properly cited.
}

seven nematode species were identified from the gut contents and intestinal tracts of small mammals, including A. agrarius, captured near the DMZ [7]. However, most of the current surveys involve wild rodent parasites found near houses or the DMZ, while data on wild rodents captured in agricultural fields near the mountains are lacking. Rodents are responsible for the spread of various zoonotic diseases and also important reservoirs of various diseases affecting people and livestock. Several investigators have studied rodent parasites from southern regions and northern areas in Korea [3-8], however, data on wild rodents captured in central regions and agricultural fields near the mountains are lacking. Therefore, this study was attempts to provide preliminary data on the intestinal helminth fauna of wild rodents inhabiting agricultural fields near the mountains in Gangwon-do (Province) and Chungcheongnam-do, Korea.

To evaluate the role of wild rodents in agricultural product contamination, we selected survey sites in rural agricultural fields beneath Chiak-san (mountain) and Gyeryong-san. The agricultural fields were located in Haenggu-dong, Wonju, Gangwon-do, Banpo-myeon Bonggog-ri, and Gongju, Chungcheongnam-do, which are located at the foothills. Beans are 
widely cultivated in the agricultural fields. Six 20-m-wide traps were set at each agricultural field. Rodents were captured alive using Sherman traps (H.B. Sherman, Tallahassee, Florida, USA) baited with peanut butter-coated saltine crackers in JulyOctober 2015 and May 2017. The rodents caught were identified using taxonomic keys [1]. The captured rodents were euthanized with chloroform following the approved animal use protocol while maintaining biosafety. Animal experimental procedures were approved by the Institutional Animal Care and Use Committee (IACUC) of Chungnam National University (CNU-00706). Necropsies were performed soon after capturing the animals. The gastrointestinal tract from the small intestine to the end of the rectum of each mouse was dissected. Then, the gut region was cut open and the contents were preserved in 10\% buffered neutral formalin solution along with fecal pellets. The helminthic worms were collected with naked eyes or under a stereomicroscope from the sediment of the intestinal content. After clearing, the collected helminths were identified using appropriate systematic keys $[9,10]$. The chi-square test and Fisher's exact test were used for statistical analyses of infection rates according to mouse species and captured areas. Statistical significance was determined using ANOVA (StatView; Abacus Concepts Inc., Berkeley, California, USA). All experiments were performed at least twice; $P$-values $<0.05$ were considered to indicate statistically significant differences.

Table 1 summarizes the intestinal helminth infection status of mice captured in agricultural fields near mountains in Gangwon-do (52 mice) and Chungcheongnam-do (31 mice), Korea.

Table 1. Helminth infection in the intestines of mice captured in agricultural fields near mountain in Gangwon-do and Chungcheongnamdo, Korea according to rodent host

\begin{tabular}{|c|c|c|c|c|c|c|c|c|c|}
\hline \multirow{3}{*}{ Helminth species } & \multicolumn{9}{|c|}{ No. of infected mice (\%) } \\
\hline & \multicolumn{3}{|c|}{ A. agrarius } & \multicolumn{3}{|c|}{ A. peninsulae } & \multicolumn{3}{|c|}{ Total } \\
\hline & $\begin{array}{l}\text { Gangwon- } \\
\text { do }(n=34)\end{array}$ & $\begin{array}{l}\text { Chung- } \\
\text { cheongnam- } \\
\text { do }(n=23)\end{array}$ & $\begin{array}{l}\text { Subtotal } \\
(n=57)\end{array}$ & $\begin{array}{l}\text { Gangwon- } \\
\text { do }(n=18)\end{array}$ & $\begin{array}{l}\text { Chung- } \\
\text { cheongnam- } \\
\text { do }(n=8)\end{array}$ & $\begin{array}{c}\text { Subtotal } \\
(n=26)\end{array}$ & $\begin{array}{l}\text { Gangwon- } \\
\text { do }(n=52)\end{array}$ & $\begin{array}{l}\text { Chung- } \\
\text { cheongnam- } \\
\text { do }(n=31)\end{array}$ & $\begin{array}{l}\text { Total } \\
(n=83)\end{array}$ \\
\hline \multicolumn{10}{|l|}{ Nematodes } \\
\hline Nippostrongylus braziliensis & $17(53.1)$ & $11(47.8)$ & $28(50.9)$ & 7 (38.9) & $5(62.5)$ & $12(46.2)$ & $24(46.2)$ & $16(51.6)$ & $40(48.2)$ \\
\hline Aspicularis tetraptera & $6(18.8)$ & $3(13.0)$ & $9(16.4)$ & $3(16.7)$ & $2(25.0)$ & 5 (19.2) & $9(17.3)$ & $5(16.1)$ & $14(16.9)$ \\
\hline Ascarid & $4(12.5)$ & $3(13.0)$ & $7(12.7)$ & $2(11.1)$ & $4(50.0)$ & $6(23.1)^{\mathrm{a}}$ & $6(11.5)$ & $7(22.6)^{b}$ & $13(15.7)$ \\
\hline Heterakis spp. & $3(9.4)$ & $3(13.0)$ & $6(10.9)$ & $3(16.7)$ & $2(25.0)$ & $5(19.2)$ & $6(11.5)$ & $5(16.1)$ & $11(13.3)$ \\
\hline \multicolumn{10}{|l|}{ Cestodes } \\
\hline Hymenolepis diminuta & $6(18.8)$ & $3(13.0)$ & $9(16.4)$ & $2(11.1)$ & $3(37.5)$ & $5(19.2)$ & $8(15.4)$ & $6(19.4)$ & $14(16.9)$ \\
\hline Unidentified & $0(0.0)$ & $1(4.3)$ & $1(1.8)$ & $0(0.0)$ & $0(0.0)$ & $0(0.0)$ & $0(0.0)$ & $1(3.2)$ & $1(1.2)$ \\
\hline Total & $26(81.2)$ & $17(73.9)$ & 43 (78.2) & $13(72.2)$ & $5(62.5)$ & $18(69.2)$ & $39(75.0)$ & $22(71.0)$ & $61(73.5)$ \\
\hline
\end{tabular}

aSignificant difference of ascarid infection rates between $A$. peninsulae and $A$. agrarius.

bSignificant difference of ascarid infection rates between Gangwon-do and Chungcheongnam-do.
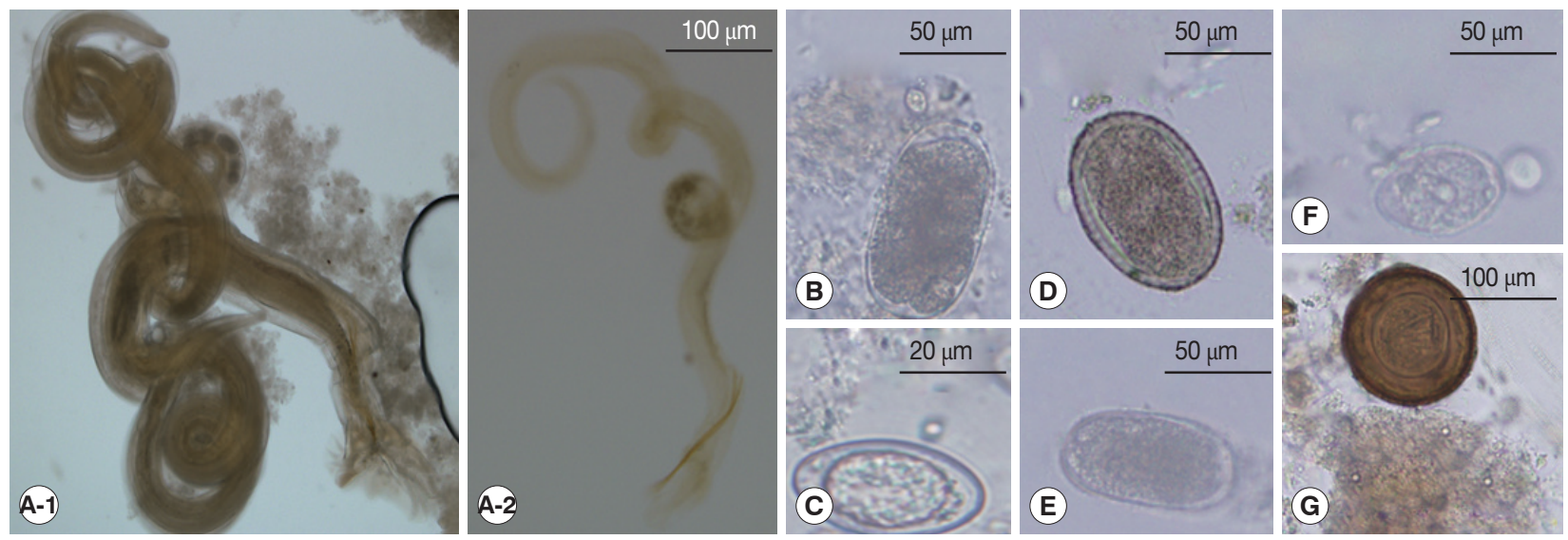

Fig. 1. Helminth and eggs from intestinal contents of wild rodents captured in the agricultural field near mountains in Gangwon-do (province) and Chungcheongnam-do, Korea. (A-1 and -2), Nippostrongylus brasiliensis adult worms, (B) A. braziliensis egg, (C) Aspicularis tetraptera egg, (D) Ascarid eggs, (E) Heterakis spp. egg, (F) Unidentified egg, and (G) Hymenolepis diminuta egg. 
Of the 83 captured mice, 61 (73.5\%) had one or more types of helminths in their intestines, which included 39 of 52 (75.0\%) and 22 of 31 (71.0\%) mice captured in Gangwon-do and Chungcheongnam-do, respectively. Among mouse species, $78.2 \%$ of A. agrarius $(\mathrm{n}=57)$ and $69.2 \%$ of $A$. peninsulae $(\mathrm{n}=26)$ were infected with various species of intestinal helminths. Six helminth species (4 nematodes, 1 trematode, and 1 cestode species) were identified (Fig. 1). Among nematodes, Nippostrongylus brasiliensis (adult worms and eggs), Aspiculuris tetraptera (eggs), ascarid (eggs), and Heterakis spp. (eggs) were detected in 40 (48.2\%), 14 (16.9\%), 13 (15.7\%), and 11 (13.3\%) mice, respectively. The cestode Hymenolepis diminuta (eggs) was detected in 14 (16.9\%) mice, and unidentified egg was also isolated. N. brasiliensis infection was more prevalent in A. agrarius than in A. peninsulae ( $50.9 \%$ vs $46.2 \%, P>0.05$ ), whereas $H$. diminuta and ascarid infections were more prevalent in $A$. peninsulae ( $19.2 \%$ vs $16.4 \%$ for $H$. diminuta, $P>0.05 ; 23.1 \%$ vs $12.7 \%$ for ascarids, $P<0.05$ ). Comparison of capture regions showed that the prevalence of ascarid infection was much higher in Chungcheongnam-do (22.6\%) than in Gangwon-do (11.5\%) $(P<0.05)$. N. brasiliensis (48.2\%) was the most prevalent nematode, followed by $H$. diminuta (16.9\%), A. tetraptera (16.9\%), ascarids (15.7\%), Heterakis spp. (13.3\%) and unidentifed eggs (1.2\%).

Rodents play important roles in seed and spore dispersal, pollination, seed predation, energy and nutrient cycling, plant succession, and species composition, and are food for many predators [1]. Few studies report the status of intestinal nematode infection in wild rodents in Korea [3-8]. Sohn et al. [3] identified four nematode species in A. agrarius in southern Korea: a heligmosomid, Syphacia obvelata, an ascarid, and a hookworm. Lee et al. [4] detected three nematode species in A. agrarius in Gangwon-do, Korea, namely, a hookworm, Syphacia sp., and Plagiorchis muris. Kim et al. [7] identified at least 1 nematode species per individual from A. agrarius captured near the DMZ in Gyeonggi-do, Korea, including Capillaria sp., H. spumosa, Heligmosomoides polygyrus, N. brasiliensis, Protospirura muris, Rictularia affinis, S. obvelata, and Trichuris muris.

In our study, 4 nematode species, namely, $N$. brasiliensis, $A$. tetraptera, ascarid, and Heterakis spp. were detected in A. agrarius and A. peninsulae, and N. brasiliensis was the dominant species. There were no significant capture site- or mouse speciesspecific differences in the prevalence of $N$. brasiliensis infection. The prevalence of $N$. brasiliensis infection in A. agrarius in our study (48.2\%) was lower than that reported by Kim et al. $(70.9 \%)$ [7]. The differences in nematode infection rate may be closely related to the environment inhabited by the rodent hosts. We surveyed agricultural fields near mountains in central and northern Korea, whereas Kim et al. [7] studied sites in the demilitarized zone of Gyeonggi Province, Korea. Ascarids are intestinal nematodes commonly found in rodents. In this study, the ascarid infection rate was $15.7 \%$, which was higher than that (2.5\%) reported by Sohn et al. [3] and Lee et al. (11.6\%) [4]. The higher prevalence in our study may be because the wild rodents were captured from agricultural fields, where contamination with stools of small mammals may be higher than in other areas. Heterakis is a genus of minute parasitic roundworms (pinworms) that is ubiquitous in rats and mice. In our study, $13.3 \%$ of the captured mice harbored intestinal Heterakis spp. This is similar to the observations of Kim et al. [7], who reported that $22.1 \%$ of $A$. agrarius captured in the DMZ in Gyeonggi Province were infected with Heterakis spp.

Unlike nematodes, trematodes and cestodes can be zoonotic pathogens. In Korea, I. hortense, P. muris, H. diminuta, and $H$. nana are common in wild rodents, which act as reservoir hosts for human infections [3-5,8,11]. In our survey, the infection rate of $H$. diminuta was $16.4 \%$ among A. agrarius and $19.2 \%$ among A. peninsulae captured in Chungcheongnam-do and Gangwon-do, while the dwarf tapeworm H. nana was not identified. This might be due to the relatively small number of mice examined.

In this study, the overall intestinal helminth infection rates of mice captured in agricultural fields near mountains were $71.0 \%$ and $75.0 \%$ in Chungcheongnam-do and Gangwon-do, respectively. These infection rates are lower than those of mice captured in southern Korea (97.0\% in Hapcheon and 98.1\% in Gurye) [3] and the DMZ in Gyeonggi Province (100\%) [7], but higher than those of northern Korean mice $72.1 \%$ for $A$. agrarius and $63.6 \%$ for A. peninsulae in Gyeonggi and Gangwon Provinces, respectively) [4]. Although A. peninsulae had higher ascarid and $H$. diminuta infection rates than A. agrarius, the overall helminth infection rate of $A$. peninsulae (78.2\%) was not significantly different from that of A. agrarius (69.2\%).

From this study, it was confirmed that there were not significant differences of intestinal helminth infection rates between wild A. agrarius and A. peninsulae, and some species of rodent intestinal helminth, $N$. brasiliensis, $H$. diminuta, A. tetraptera and Heterakis spp. are prevalent rather than zoonotic ones. However, this study has some limitations such as the surveyed number of mice were not enough, and the parasite numbers were not presented quantitatively. 


\section{ACKNOWLEDGMENTS}

The present research has been supported by Rural Development Administration, the Republic of Korea (project no. PJ01085903). This work was supported by research fund of Chungnam National University.

\section{CONFLICT OF INTEREST}

We have no conflict of interest related to this study.

\section{REFERENCES}

1. Singleton GR, Hinds LA, Krebs CJ, Spratt DM. Rats, Mice and People: Rodent Biology and Management. Canberra, Australia. Clarus Design. 2003, pp 181-216.

2. Pakdel N, Naem S, Rezaei F, Chalehchaleh AA. A survey on helminthic infection in mice (Mus musculus) and rats (Rattus norvegicus and Rattus rattus) in Kermanshah, Iran. Vet Res Forum 2013; 4: 105-109.

3. Sohn WM, Na BK, Song HJ, Kim CM, Nam GJ. Intestinal helminthic infections in striped field mice, Apodemus agrarius, from two southern regions of Korea. Korean J Parasitol 2014; 52: 419423.

4. Lee YI, Pyeon HJ, Seo M. Intestinal Parasites among wild rodents in Northern Gangwon-do, Korea. Korean J Parasitol 2013; 51:
603-606.

5. Chai JY, Park JH, Jung BK, Guk SM, Kim JL, Shin EH, Klein TA, Kim HC, Chong ST, Baek LJ, Song JW. Echinostome infections in the striped-field mouse, Apodemus agrarius, and the Ussuri whitetoothed shrew, Crocidura lasiura, caught near the demilitarized zone, Gyeonggi-do (Province), Republic of Korea. Korean J Parasitol 2009; 47: 311-314.

6. Chai JY, Park JH, Guk SM, Kim JL, Kim HJ, Kim WH, Shin EH, Klein TA, Kim HC, Chong ST, Song JW, Baek LJ. Plagiorchis muris infection in Apodemus agrarius from northern Gyeonggi-do (Province) near the demilitarized zone. Korean J Parasitol 2007; 45: 153-156.

7. Kim DG, Park JH, Kim JL, Jung BK, Jeon SJ, Lim H, Lee MY, Shin EH, Klein TA, Kim HC, Chong ST, Song JW, Baek LJ, Chai JY. Intestinal nematodes from small mammals captured near the demilitarized zone, Gyeonggi province, Republic of Korea. Korean J Parasitol. 2015; 53: 135-139.

8. Seo BS, Rim HJ, Yoon JJ, Koo BY, Hong NT. Studies on the parasitic helminths of Korea: III. Nematodes and cestodes of rodents. Korean J Parasitol 1968; 6: 123-131.

9. Flynn RJ. Parasites of Laboratory Animals. 1st ed. Ames, USA. Iowa State University Press. 1973. pp 120-320.

10. Category:Parasites of rodents. [Internet]; Available from: https:// en.wikipedia.org/wiki/Category:Parasites of rodents.

11. Seo BS, Cho SY, Hong ST, Hong SJ, Lee SH. Studies on parasitic helminths of Korea 5. Survey on intestinal trematodes of house rats. Korean J Parasitol 1981; 19: 131-136. 